\title{
Pharmacological Treatment of Patients with Paraphilic Disorders and Risk of Sexual
}

Offending: An International Perspective

Daniel Turner ${ }^{1,2}$, Julius Petermann ${ }^{1}$, Karen Harrison ${ }^{3}$, Richard Krueger $^{4} \&$ Peer Briken ${ }^{1}$

${ }^{1}$ Institute for Sex Research and Forensic Psychiatry, University Medical Centre HamburgEppendorf, Hamburg, Germany

${ }^{2}$ Department of Psychiatry and Psychotherapy, University Medical Centre Mainz, Johannes Gutenberg University Mainz, Germany

${ }^{3}$ School of Law \& Politics, University of Hull, Hull, UK.

${ }^{4}$ Columbia University, College of Physicians and Surgeons, Department of Psychiatry, New York, USA

This preprint has been accepted for publication in WORLD JOURNAL OF BIOLOGICAL PSYCHIATRY (10/2017) 


\begin{abstract}
Objectives

The present study aims to evaluate existing policy and practice relating to the use of pharmacological treatments with patients suffering from paraphilic disorders who are at risk of committing further sexual offences.

\section{Methods}

A systematic literature search was conducted to document current legal policies across 26 different countries. Additionally, a questionnaire assessing the practice of pharmacological treatment was sent to practitioners involved in the treatment of patients with paraphilic disorders.
\end{abstract}

\title{
Results
}

Legal policies concerning the preconditions of using pharmacological treatments differ considerably between countries and for most jurisdictions do not exist. Drawing on the responses of 178 practitioners, pharmacological agents are a useful addition to psychotherapeutic interventions, especially with those patients classified as medium to high risk for sexually violent behaviours. It would appear that most patients are medically examined, are informed of the risks and possible side effects before treatment commences and are also obliged to sign a consent form.

\section{Conclusions}

Although pharmacological agents can be seen as an intrusion into a patients' sexual selfdetermination, results indicate that ethical and clinical standards are being met in the majority of cases. However, further promotion of current WFSBP-treatment guidelines would help to standardize practice across North American and European countries.

Key words: Paraphilic Disorder, Sexual Offenders, Androgen Deprivation Therapy, Antiandrogens, WFSBP-treatment guidelines 


\section{Introduction}

The presence of paraphilic disorders in individuals has been found to be a major risk factor in sexual offending, with at least one paraphilic disorder being found in approximately $50 \%$ of sexual offender samples (Eher et al. 2010; Hanson \& Morton-Bourgon 2005).

Recognizing the close link between these disorders and sexual offending, the World Federation of Societies of Biological Psychiatry (WFSBP) treatment guidelines set out a hierarchy of drugs to be used with those who present with paraphilic fantasies and impulses and are deemed risky in terms of criminal behaviour. According to the guidelines, clinicians should first use selective-serotonin-reuptake-inhibitors (SSRIs), followed by steroidal antiandrogens (cyproterone acetate (CPA) or medroxyprogesterone acetate (MPA)) and finally gonadotropin-releasing-hormone-agonists (GnRH-agonists) (Thibaut et al. 2010). On the basis that both steroidal antiandrogens and GnRH-agonists lead to a considerable decrease in serum testosterone levels they are referred to as androgen deprivation therapy (ADT). Factors which clinicians usually take into consideration when making the decision whether or not ADT should be used include a history of previous treatment failures and sexual violations while either in detention or under community supervision (Turner et al. 2014).

Although pharmacological agents are frequently used in the treatment of paraphilic disorders (Basdekis-Jozsa et al. 2013; McGrath et al. 2010), effectiveness studies are limited (e.g. Khan et al. 2015; Koo et al. 2013; Kraus et al. 2006; Maletzky et al. 2006). Moreover, and especially in relation to ADT, there are a variety of negative side effects including weight gain, gynaecomastia, reduced testicle volume, hot flushes, reduced bone mineral density, and hepatotoxicity. These and other concerns, relating to issues such as consent, have provoked ethical questions concerning their use (Basdekis-Jozsa et al. 2013; Cherrier et al. 2010; Gooren 2011; Harrison 2008; Khan \& Mashru 2016).

Due to such concerns, it would be desirable to first harmonize and then standardize the management and treatment of those paraphilic patients who present a risk of sexually violent 
behaviours, which will ensure that all ethical and medical standards are being met. For example, this should include unity in decisions relating to practice including: 1) Who is suitable for pharmacological treatment, 2) Who decides when pharmacological agents are to be used , 3) Whether treatment is provided on a voluntary or mandatory basis, and 4) In which institutions paraphilic patients should be treated. This task of harmonising and standardising practice is important, not least because of increasing internationalization and globalization. It is now not uncommon for paraphilic patients who have committed a sexual offence to be convicted, incarcerated, and receive treatment outside of their home country or to be transferred back to their country of origin following release from prison or comparable institution (Salize et al. 2005). Furthermore, with a rise in child trafficking for sexual purposes, especially throughout European and North American countries, the synchronization of practice is essential (Koops et al. 2017) and should be based on sound empirical data (Salize et al. 2005).

Given this, the present study looked to evaluate the current practice of pharmacotherapy with patients suffering from paraphilic disorders in three different geographical regions: North America, Western Europe and Eastern Europe. These areas were chosen as they share a broad historical and legal background. The research involved collecting and assessing the opinions of practitioners engaged in administering pharmacological treatment to individuals with a paraphilic disorder. Based on current research it is reasonable to conclude that most paraphilic patients treated with pharmacological agents have been convicted of a sexual offence. To enable a precise analysis and interpretation of practitioners' views it was therefore important to assess the legislative basis for this treatment. This approach enabled us to analyse and discuss the results in light of differing legal systems and the recommendations provided by the WFSBP guidelines (Thibaut et al. 2010).

\section{Materials and Methods}




\section{Legislation and policy}

In order to obtain information on the legislative basis for treating paraphilic patients at risk of committing sexual offences with pharmacotherapy, a systematic literature search was conducted in the included countries looking for relevant legal frameworks or policy documents. This was achieved using PubMed, Google, and Google Scholar and the search terms: "sexual offender treatment," "antiandrogens," "chemical castration," "Androgen Deprivation Therapy" AND "law," "legal," "directive," AND the single North American and European countries. Only publications in German and English were reviewed. To ensure that information on legal policies was up-to-date, the search was restricted to data published between January 2000 and May 2017. Where no reliable information could be found for a country (for example where only newspaper reports but no scientific publications were identified) relevant experts from these selected countries were directly contacted and information obtained.

\section{Expert opinion on the current clinical practice}

\section{Participants}

Participants of the questionnaire were identified using Google and the terms: "forensic psychiatry," "forensic psychology," "forensic outpatient clinic," "forensic hospital," "psychiatry," "prison," AND the single countries of North America and Europe. The search was conducted in English. The first 100 results of every search were analysed looking for individuals who were potentially involved in the treatment of sexual offenders. When email addresses could be identified, individuals were contacted and invited to participate in the study. The study invitation was also sent to members of the International Association for the Treatment of Sexual Offenders, the American Association for the Treatment of Sexual Abusers, the European Association of Psychology and Law, the European Psychiatric 
Association, the World Psychiatric Association, and the World Health Organization Health in Prisons Programme.

In total 729 people responded to the invitation and submitted partial or fully completed questionnaires. For meaningful analyses, however, only those participants who completed the entire questionnaire were included. This reduced the sample size to 178 individuals $(24.4 \%$ of the initial sample). The three regions (North America, Western Europe and Eastern Europe) yielded participants from 26 different countries: the United States of America (US), Canada, Austria, Belgium, Denmark, England, Finland, France, Germany, Greece, Ireland, Italy, The Netherlands, Portugal, Spain, Sweden, Switzerland, Croatia, Czech Republic, Estonia, Hungary, Latvia, Poland, Russia, Slovakia, and Slovenia. Table 1 presents an overview of the socio-demographic information of these participants.

*** Please insert table 1 about here ***

\section{Questionnaire and data acquisition}

Data acquisition was achieved through a self-constructed questionnaire. All participants were informed of the study's objectives, were assured of confidentiality, and notified of ethical approval. This was given by the ethical review board of the Chamber of Psychotherapists, Hamburg, Germany. The questionnaire was programmed using Questback EFS Survey 10.2 (Questback GmbH, Cologne, Germany). All raw data were saved on Questback servers, which met all national requirements concerning data protection and safety according to the German Federal Office of Information Security (http://www.questback.com/de/datenschutz-datensicherheit.html).

\section{Statistical Analyses}


All statistical analyses were conducted using IBM SPSS Statistics for Macintosh, Version 22.0 (Amonk, NY, USA). Answers were compared utilizing ANOVAs for continuous variables and chi-square tests for categorical variables. Furthermore, results were also compared between those countries (or US states) that have legal statutes allowing for mandatory $\mathrm{ADT}$ and those that provide ADT on a voluntary basis. Only those participants who had actually prescribed pharmacological agents for treating paraphilic disorders were included in this last step of the analyses.

\section{Results}

\section{Legislation and policy}

In the US, SSRIs, MPA, and GnRH-agonists are commonly used in the treatment of paraphilic disorders (McGrath et al. 2010). This is the case, even though their use for this purpose is off label, i.e. it deviates from Federal Drug Administration approval. In Canada and Europe SSRIs, CPA and GnRH-agonists are normally used (Holoyda \& Kellaher 2016). European authorities approved the use of CPA in the treatment of paraphilic disorders in 1973 and GnRH-agonists in 2007. Triptorelin is currently the only GnRH-agonist officially approved for use with severe paraphilic disorders (Thibaut et al. 2010), although other GnRHagonists (goserelin, buserelin, and leuprolide) are commonly used as well.

Historically, eight US states (California, Florida, Iowa, Louisiana, Oregon, Montana, Wisconsin, Georgia), had legal statues allowing for the use of ADT in paraphilic patients who had committed a sexual offence (Douglas et al. 2013); although actual implementation in each state varied. More recently, this legislation has been repealed in both Georgia and Oregon (Vaillancourt 2012). ADT is currently provided on a voluntary basis in Montana and Wisconsin and available on a mandatory basis (where a paraphilic patient has been convicted of at least two sexual offences) in California, Florida, Iowa, and Louisiana (del Busto \& Harlow 2011; Scott \& Holmberg 2003). In Florida ADT can be used with all paraphilic 
patients who have committed a sexual offence, while in the remaining five states it can only be administered to those patients who have sexually abused children (age of the victim: < 13years in California, Iowa, Louisiana, Wisconsin; $<16$ years in Montana) (Scott \& Holmberg 2003). Interestingly, in Texas, while there is legal provision for surgical castration, there is no legal basis for the use of ADT (Douglas et al. 2013). Despite a lack of legal provisions, ADT and/or other pharmacological agents are used in most other states of the US (McGrath et al. 2010). Of those states that do have a legislative basis, none require additional psychotherapy nor have specifications concerning the medical monitoring of side effects during pharmacological treatment (Scott \& Holmberg 2003; Vaillancourt 2012).

In Europe, almost all countries that permit the use of ADTs do so on a voluntary basis. In some of these countries, for example Belgium, Denmark, Estonia, and Sweden, psychiatric treatment, including pharmacological treatment, can be implemented as a formal condition of parole (Douglas et al. 2013; Koch-Arzberger et al. 2011; Kristensen et al. 2011). In Denmark, for example, individuals with a paraphilic disorder who were convicted of a sexual offence and who pleaded guilty can voluntarily choose to be treated with ADT (Aagaard 2014). ADT can be implemented as a precondition of parole or probation or as a condition of release from an indefinite sentence (Aagaard 2014). In all cases the Danish Legal Medical Council has to approve the treatment, once extensive mental and physical examinations have been completed, although the final decision about an individual's suitability is made by the Prison and Probation Service (Aagaard 2014).

In other European countries there is no legal connection between ADT treatment and parole. German law states that people with a severe sexual preference disorder can be treated with ADT on a voluntary basis if they have been extensively informed about the risks and negative side effects of the treatment and about all other treatment options. This also applies to adolescents, as long as their legal guardian has given informed consent (Law on voluntary castration and other treatment methods; [Gesetz über die freiwillige Kastration und andere 
Behandlungsmethoden; KastrG]; inception on $15^{\text {th }}$ Feb. 1970; last change: $10^{\text {th }}$ Nov. 2016). In Switzerland Article 434 of the Civil Code allows for the mandatory use of medications including ADT (although not explicitly mentioned) if the patient is at risk of causing harm to himself or to others, suggesting that theoretically ADT could be applied to those individuals who display a high risk for future criminal behaviours. Despite such legislation, however, in practice ADT is only provided for on a voluntary basis and does not have any association with early release or parole (Tileman 2016). Moldova, Estonia, Canada, Hungary, Austria, France, Norway, the Netherlands, Finland, Iceland, Italy, Latvia, Spain, the Czech Republic, and the United Kingdom (UK) also permit the use of ADT on a voluntary basis. To our knowledge there is no link between the undertaking of treatment and early release or parole in these countries (Akbaba 2015; Directorate General For Internal Policies 2013; Koshevaliska 2014; McAlinden 2012). Moreover, although pharmacological treatments and, especially, ADT are used in these countries, there is very little in terms of legal regulations. No such laws exist, for example, in the UK.

In 2010, Poland became the first European country to introduce court-ordered mandatory pharmacological treatment for anyone found guilty of having sexually abused a child under the age of 15 years (McAlinden 2012). Macedonia has also recently enacted similar legislation (Koshevaliska 2014). Here, first time sexual offenders can choose to be treated with ADT on a voluntary basis in order to reduce the prison sentence (Ratkoceri 2017). Furthermore, all individuals who have been convicted of a second sexual offence can be treated on a mandatory basis as long as the court believes that the individual is at risk of committing another sexual offence (Koshevaliska 2014; Ratkoceri 2017). As far as we could determine there seems to be no specification that the patient has to be diagnosed with a paraphilic disorder in order to fall into this category. The Russian Penal Code states that a court can impose "compulsory measures of a medical nature" (Article 97) on persons aged 18 or older who have committed a sexual offence against a child (classed as under 14 years of 
age) and who suffer from a sexual preference disorder (Tileman 2016). The offender also has to be at risk of committing further damage or danger to himself or others (Tileman 2016). In 2012, Moldova also introduced the use of mandatory ADT for anyone convicted of having sexually abused a child aged 15 years or under (Tileman 2016), however, this was repealed in 2013 because of human rights concerns.

As far as we have been able to determine, Greece and Portugal are the only European countries in which paraphilic patients who have committed a sexual offence are not treated with ADT (2017 personal email communication between O. Giotakos and the first author for Greece, and personal email communication between R. Barroso and the first author for Portugal, both unreferenced). We were unable to find any reliable information for Croatia, Slovakia, or Slovenia ${ }^{1}$.

\section{Expert opinion on current clinical practice}

Where multiple answers were allowed, forensic-psychiatric hospitals (North America: 88.4\%, Western Europe: $85.0 \%$, Eastern Europe: $65.7 \%$ ) were cited as the most common institutions in which paraphilic patients convicted for a sexual offence were treated using pharmacological agents. This was followed by outpatient care settings (North America: 83.7\%, Western Europe: 72.0\%, Eastern Europe: 51.4\%), and prisons (North America: 44.2\%, Western Europe: 53.0\%, Eastern Europe: 31.4\%) (Forensic-psychiatric hospitals = outpatient care settings $>$ prisons for all three regions) $)^{2}$. Asking participants which pharmacological agents were used most frequently in treating paraphilic disorders in their country (only one answer was allowed), participants from North American and Western European countries indicated that SSRIs were used most frequently (North America: 65.1\%; Western Europe:

\footnotetext{
${ }^{1}$ None of the contacted experts replied to our request on providing us with information about the legal practice concerning the use of ADT in the aforementioned countries.

${ }^{2}$ Significant differences refer to $\mathrm{p}<.05$
} 
41.0\%), followed by steroidal antiandrogens (North America: 14.0\%; Western Europe: 17.0\%), GnRH-agonists (North America: 7.0\%; Western

Europe: 13.0\%), and antipsychotics (North America: 2.3\%; Western Europe: 10.0\%) (North America: SSRIs $>$ antiandrogens $=$ GnRH-agonists $>$ antipsychotics; Western Europe: SSRIs $>$ antiandrogens $=\mathrm{GnRH}$-agonists $=$ antipsychotics $)^{2}$. Participants from Eastern European countries reported that steroidal antiandrogens (31.4\%) and antipsychotics $(28.6 \%)$ were used more often than SSRIs (5.7\%) and GnRH-agonists (2.9\%) (Eastern Europe: Antiandrogens = antipsychotics $>$ SSRIs $=$ GnRH agonists $)^{2}$.

An overview of the participants' opinions as to whether pharmacological agents should ever be used in the treatment of sexually deviant behaviours in individuals convicted of a sexual offence is presented in Table 2. This also shows what others factors have to be certified before treatment can begin, for example, whether patients are informed about the possible risks and side effects, whether patients have to give written informed consent, and whether patients are notified that their consent can be revoked. Perhaps unsurprisingly, the more high-risk a patient is in terms of showing future sexually violent behaviours, the more appropriate practitioners thought the use of ADT treatment was. This view was shared by most participants across the three regions and is presented in Table 3.

*** Please insert table 2 and 3 about here $* * *$

In order to compare the opinion of participants from countries with different legal provisions the sample was divided into participants coming from those countries or US states which provide ADT on a voluntary basis (U.K., Denmark, Netherlands, Czech Republic, Spain, Canada, Germany, Belgium, Austria, France, Switzerland, Sweden, Finland, Estonia, Italy, Latvia, Portugal, Ireland, U.S. state except California, Florida, Iowa, Louisiana; $n=57$ ) and those that impose it mandatorily (California, Florida, Iowa, Louisiana, Poland and Russia; 
$n=12$ participants). This is presented in Table 4 . Due to incomplete information concerning the legal basis of ADT in Croatia, Slovakia, and Slovenia, participants from these countries were excluded from this analysis.

*** Please insert table 4 about here ***

\section{Discussion}

Although pharmacological agents are used in almost all North American and European countries for the treatment of those paraphilic patients who are at risk of committing further sexual offences, most countries do not have official laws regulating their use. Moreover, even where legal statutes do exist, these vary considerably and therefore do not present us with a unified or standardised approach. Most jurisdictions do not specify that pharmacological treatment should be restricted to patients with paraphilic disorders and thus it appears that such treatment can be given to any individual at risk of committing further sexual offences; this is especially the case in those countries which have mandatory treatment options. Where there is no therapeutic need, the use of pharmacological treatment here can only be viewed as punitive, raising medical ethics questions. Moreover, previous research has indicated that even where legal policies do exist they are not necessarily followed in practice. For example, although there is no official link between pharmacotherapy and early release in Germany, Briken and colleagues have found that those patients with a paraphilic disorder currently placed in prison or similar institutions who decide to be treated with ADT are more likely to be considered for home leave than those who are not treated (Briken et al. 2009).

Comparing the treatment numbers from our study with earlier studies it can be concluded that the percentage of paraphilic patients being treated with ADT has remained quite stable across the last two decades. Around $10 \%$ to $15 \%$ of patients who have committed a sexual offence are treated with ADT with the aim being to reduce paraphilic fantasies and 
urges (Cosyns 1999; Czerny et al. 2002; Turner et al. 2013). This indicates that although current meta-analyses are sceptical about the actual effectiveness of pharmacological agents (Khan et al. 2015; Langström et al. 2013; Schmucker \& Lösel 2015), clinical experience suggests that for some paraphilic patients medication is a useful addition to psychotherapeutic interventions and, as such, its use is being recommended by both clinicians and the WFSBP guidelines (Thibaut et al. 2010). Recent research suggests that the agents used in the treatment of paraphilic disorders, seem to be helpful in the treatment of men with a hypersexual disorder as well (Kaplan \& Krueger 2010; Wainberg et al. 2006; Safarinejad 2009). For example, Winder et al. (2017) reported on a sample of 127 adult male prisoners serving sentences for sexual offences in a UK prison who were treated with either SSRIs or steroidal antiandrogens for hypersexual disorder. Both agents led to a significant decrease in 1) the number of days on which participants masturbated to orgasm, 2) the time spent thinking about sex, and 3) the strength of sexual urges. Initial effects were noticed within one month and increased over a period of six months (Winder et al. 2017). This treatment approach could be due to similarities of paraphilic and hypersexual disorders, because both types of disorders frequently involve sexual behaviour that cannot be controlled by the patient (Kaplan \& Krueger 2010; Krueger \& Kaplan 2001). However, the relationship between hypersexual behaviours and sexual offending is less clear compared to the association between paraphilic disorders and sexual offending and only few individuals presenting with hypersexual behaviours sexually offend (Klein et al. 2015; Turner et al. 2014).

Although the current state of research suggests that pharmacological agents are useful in the reduction of general sexual drive, their use is accompanied by many ethical concerns. This is especially the case for ADT, where it has been argued that it restricts a patient's ability to have a self-determined sexual life and consequently may violate basic human rights (Basdekis-Jozsa et al. 2013). Depending on the specific dosage and application method ADT can lead to a complete decline of sexual fantasies, urges and behaviours also including non- 
paraphilic sexual behaviours. This suggests that ADT should be reserved for those patients with the most intense paraphilic disorders, as it would be ethically questionable to prevent the possibility of having a functional sex life in patients with less severe paraphilic disorders.

In order to ensure that medical and ethical standards are met and that the harmful nature of the treatment is kept to a minimum, all pharmacological treatments must be carried out on a completely voluntary basis and should be restricted to patients with a paraphilic disorder. To guarantee voluntary treatment the WFSBP guidelines recommend extensively informing all patients about potential risks and side effects, in addition to perceived benefits before asking for written consent. It is only through the provision of adequate information that consent can be informed consent. This is important bearing in mind that current laws do not specify such requirements. Overall, our study reports that most, but not all, treatment providers meet these preconditions. However, it has to be noted that in those countries where taking medication is a precondition of early release or parole it is questionable whether voluntary and informed consent can ever be achieved. Even where there is no official link to early release or parole it cannot be ruled out that a paraphilic patient who is placed in prison or a comparable institution is only consenting to treatment because he believes that taking part in such a program will be viewed positively by the supervisory authorities (Harrison 2008). In this context, one surprising finding is that even from those countries or US states who legislate for mandatory treatment, the majority of participants nevertheless stated that patients still had to give their written informed consent before pharmacological treatment would commence. This finding could show that treatment providers do not agree with this mandate and thus ask for their patients' written informed consent despite not actually needing it. Moreover, mandatory treatment can only be applied to certain patients fulfilling specific criteria and only a minority of individuals are likely to fulfil these criteria. It could therefore be the case that these practitioners are actually treating many more paraphilic patients voluntarily than they are on a mandatory basis. However, even if the number of patients who 
are being treated mandatorily is very small, ethically the most appropriate approach would be to provide voluntary treatment for all patients with a paraphilic disorder and to decouple decisions on parole from those involving pharmacological treatment.

Furthermore, in line with WFSBP guidelines, the vast majority of participants indicated that psychotherapy is provided in conjunction with pharmacological treatment. This is especially noteworthy, considering that where legal statutes exist, they do not explicitly require this additional psychotherapy. Taken together, these findings suggest that in many cases clinical practice seems to be more advanced and more ethically sound than the legislation that governs it.

The findings of the present study are limited because they only provide a subjective view about the practice of pharmacological sexual offender therapy and do not necessarily represent the actual clinical practice in the included countries and states. Representativeness of the findings is also limited due to the high dropout rate and the number of participants from some single countries being quite small. Although reliable evidence was found concerning the legal policies for most countries, we did not examine actual legislation. Such an approach would have been beyond the scope of the present study. However, this would be a worthwhile goal for future studies. Furthermore, any connection between taking medication and early release should be urgently addressed as such a link threatens the validity of informed consent for individuals treated under these conditions. Future research should also compare actual practice and policy concerning the use of pharmacological treatment for paraphilic disorders in adolescents who are at risk of sexual offending. This should be done on a pan-country basis and assess this in light of recently published WFSBP treatment-guidelines on adolescents (Thibaut et al. 2016).

Differences in policy and legislation exist in various countries resulting in uncertainty for some treatment providers, as is shown by the discrepancies between the participants' answers and the actual legal policies of the countries and states in which they practice. 
Furthermore, legal policies in some countries are arguably ethically and medically unsound. Much work therefore remains in terms of harmonising and standardizing practice, especially in the case of individuals who have been in contact with the legal system. Although current guidelines help to define the preconditions and circumstances of treatment, the actual decision about whether or not a paraphilic patient is suitable for pharmacological treatment should always be made on a case by case basis. Furthermore, because pharmacological treatment and especially ADT can limit a patients' freedom and human rights, it is extremely important that ethical and clinical standards, some of which are stated in the WFSBP guidelines, be followed and that further surveys and research concerning pharmacological treatment be conducted.

\section{Acknowledgments}

The present study was part of the dissertational thesis of Dr. Julius Petermann.

\section{Disclosure of interest}

The authors report no conflict of interest. 


\section{References}

Aagaard L. 2014. Chemical castration of Danish sex offenders. J Bioeth Inq. 11: 117-118.

Akbaba, Z. B. (2015). The permissibility of pharmacotherapy for paedophilic sex offenders in the light of the rights protected under the European Convention on Human Rights [dissertation]. Leicester: University of Leicester.

Basdekis-Jozsa R, Turner D, Briken P. 2013. The Wiley-Blackwell handbook of legal and ethical aspects of sex offender treatment and management. Chichester: John Wiley \& Sons. Chapter 18, Pharmacological treatment of sexual offenders and its legal and ethical aspects; pp. 302-320.

Briken P, Welzel K, Habermann N, Hill A, Berner W. 2009. Antiandrogene Therapie und Lockerungen bei Sexualstraftätern im Maßregelvollzug Berlin [Antiandrogenic pharmacotherapy of sexual offenders and home leave steps in the forensic psychiatric hospital Berlin]. Psychiatr Prax. 36: 232-237.

Cherrier MM, Borghesani PR, Shelton AL, Higano CS. 2010. Changes in neuronal activation patterns in response to androgen deprivation therapy: a pilot study. BMC Cancer. 10: 18.

Cosyns P. 1999. Treatment of sexual abusers in belgium. J Interpersonal Violence. 14: 396410.

Czerny J-P, Briken P, Berner W. 2002. Antihormonal treatment of paraphilic patients in German forensic psychiatric clinics. 17: 104-106.

del Busto E, Harlow MC. 2011. International perspectives on the assessment and treatment of sexual offenders: theory, practice and research. Oxford:Wiley-Blackwell. Chapter 29, American sexual offender castration treatment and legislation; pp. 543-571.

Directorate General For Internal Policies. Policy Department C: Citizens' Rights And Constitutional Affairs. (2013). Overview of the worldwide best practices for rape prevention and for assisting women victims of rape. Brussels (Belgium): European 
Parliament.

Douglas T, Bonte P, Focquaert F, Devolder K, Sterckx S. 2013. Coercion, incarceration, and chemical castration: an argument from autonomy. J Bioeth Inq. 10: 393-405.

Eher R, Rettenberger M, Schilling F. 2010. Psychiatrische Diagnosen von Sexualstraftätern: Eine empirische Untersuchung von 807 inhaftierten Kindesmissbrauchstätern und Vergewaltigern [Psychiatric diagnoses of sexual offenders: an empirical study of 807 incarcerated child sexual abusers and rapists]. Z Sexualforsch. 23: 23-35.

Gooren LJ. 2011. Ethical and medical considerations of androgen deprivation treatment of sex offenders. J Clin Endocrinol and Metab, 96: 3628-3637.

Hanson RK \& Morton-Bourgon KE. 2005. The characteristics of persistent sexual offenders: a meta-analysis of recidivism studies. J Consul Clin Psychol. 73: 1154-1163.

Harrison K. 2008. Legal and ehtical issues when using antiandrogenic pharmacotherapy with sex offenders. Sexual Offender Treatment. 3.

Holoyda BJ, Kellaher DC. 2016. The biological treatment of paraphilic disorders: an updated review. Curr Psychiatry Rep. 18: 19.

Kaplan MS, Krueger RB. 2010. Diagnosis, assessment, and treatment of hypersexuality. J Sex Res. 47: 181-198.

Khan O, Ferriter M, Huband N, Powney MJ, Dennis JA, Duggan C. 2015. Pharmacological interventions for those who have sexually offended or are at risk of offending. Cochrane Database Syst Rev. 2: Art. No.: CD007989.

Khan O, Mashru A. 2016. The efficacy, safety and ethics of the use of testosteronesuppressing agents in the management of sex offending. Current Opin Endocrinol Diabetes Obes. 23: 271-278.

Klein V, Schmidt A, Turner D, Briken P. Are sex drive and hypersexuality associated with pedophilic interest and child sexual abuse in a male community sample? Plos One. 10: e0129730. 
Koch-Arzberger C, Bott K, Kerner H-J, Reich K. 2011. Rückfallgefährdete Sexualstraftäter in Hessen [Sexual offenders at risk for recidivism in Hesse, Germany]. Wiesbaden (Germany): Hessisches Landeskriminalamt.

Koo KC, Shim GS, Park HH, Rha KH, Choi YD, Chung BH, Hong SJ, Lee JW. 2013. Treatment outcomes of chemical castration on Korean sex offenders. J Forensic Leg Med. 20: 563-566.

Koops T, Turner D, Neutze J, Briken P. 2017. Child sex tourism - prevalence and risk factors for its use in a German community sample. BMC: Public Health, 17:344.

Koshevaliska O. 2014. Medical pharmacological treatment (a.k.a. chemical castration) in the Macedonian Criminal Code. Balkan Soc Sci Rev. 4: 25-45.

Kraus C, Strohm K, Hill A, Habermann N, Berner W, Briken P. 2006. Selective serotonine reuptake inhibitors (SSRI) in the treatment of paraphilia. Fortschr Neurol Psychiatr. 75: $351-356$.

Kristensen E, Fristed P, Fuglestved M, Grahn E, Larsen M, Lillebaek T, Sorensen T. 2011. International perspectives on the assessment and treatment of sexual offenders: theory, practice and research. Chichester (UK): Wiley \& Sons. Chapter 12, The Danish sexual offender treatment and research program; p. 251-262.

Krueger RB, Kaplan, MS. 2001. The paraphilic and hypersexual disorders: An overview. J Psychiatric Pract. 7: 391-403.

Langström N, Enebrink P, Laurén E.-M, Lindblom J, Werkö S, Hanson RK. 2013. Preventing sexual abusers of children from reoffending: systematic review of medical and psychological interventions. BMJ. 4630: 347-358.

Maletzky BM, Tolan A, McFarland B. 2006. The Oregon depo-Provera program: a five-year follow-up. Sex Abuse. 18: 303-316.

McAlinden, A-M. 2012. The governance of sexual offending across Europe: Penal policies, political economies and the institutionalization of risk. Punishment Society. 14: 166-192. 
McGrath RJ, Cumming GF, Burchard BL, Zeoli S, Ellerby L. 2010. Current practices and emerging trends in sexual abuser management: the Safer Society 2009 North American survey. Brandon: Safer Society Press.

Ratkoceri V. 2017. Chemical castration as a security measure in the criminal legislation of the Republic of Macedonia. Int J Soc Sci Edu Res. 3: 356-360.

Safarinejad MR. 2009. Treatment of nonparaphilic hypersexuality in men with long-acting analog of gonadotropin-releasing-hormone. J Sex Med. 6: 1151-1164.

Salize HJ, Lepping P, Dressing H. 2005. How harmonized are we? Forensic mental health legislation and service provision in the European Union. Crim Behav Ment Health. 15: $143-147$.

Schmucker M, Lösel F. 2015. The effects of sexual offender treatment on recidivism: an international meta-analysis of sound quality evaluations. J Exp Crimino. 11: 597-630.

Scott CL, Holmberg T. 2003. Castration of sex offenders: prisoners' rights versus public safety. J Am Acad Psychiatry Law. 31: 502-509.

Thibaut F, Bradford JM, Briken P, De La Barra F, Häßler, F, Cosyns P, WFSBP Task Force on Sexual Disorders. 2016. The World Federation of Societies of Biological Psychiatry (WFSBP ) guidelines for the treatment of adolescent sexual offenders with paraphilic disorders. World J Biol Psychiatry. 17: 2-38.

Thibaut F, De La Barra F, Gordon H, Cosyns P, Bradford JM, WFSBP Task Force on Sexual Disorders. 2010. The World Federation of Societies of Biological Psychiatry (WFSBP) guidelines for the biological treatment of paraphilias. World J Biol Psychiatry. 11: 604655.

Tileman H. 2016. Review of laws providing for chemical castration in criminal justice. Pasar Minggu (South Jakarta): Institute for Criminal Justice Reform.

Turner D, Basdekis-Jozsa R, Briken P. 2013. Prescription of testosterone-lowering medications for sex offender treatment in German forensic-psychiatric institutions. J Sex 
Med. 10: 570-578.

Turner D, Basdekis-Jozsa R, Dekker A, Briken P. 2014. Which factors influence the appropriateness of testosterone-lowering medications for sex offenders? A survey among clinicians from German forensic-psychiatric institutions. World J Biol Psychiatry.15: $472-478$.

Turner D, Schoettle D, Bradford J, Briken P. 2014. Assessment methods and management of hypersexuality and paraphilic disorders. Curr Opin Psychiatry. 27: 413-422.

Vaillancourt SP. 2012. Chemical castration: how a medical therapy became punishment and the bioethical imperative to return to a rehabilitative model for sex offenders [dissertation]. Winston-Salem (NC): Wake Forest University.

Wainberg ML, Muench F, Morgenstern J, Hollander E, Irwin TW, Parsons JT, Allen A, O'Leary A. 2006. A double-blind study of citalopram versus placebo in the treatment of compulsive sexual behaviors in gay and bisexual men. J Clin Psychiatry. 67: 1968-1973.

Winder B, Lievesley R, Elliot H, Hocken K, Faulkner J, Norman C, Kaul A. 2017. Evaluation of the use of pharmacological treatment with prisoners experiencing high levels of hypersexual disorder. J Forensic Psychiatry Psychol. epub ahead. 

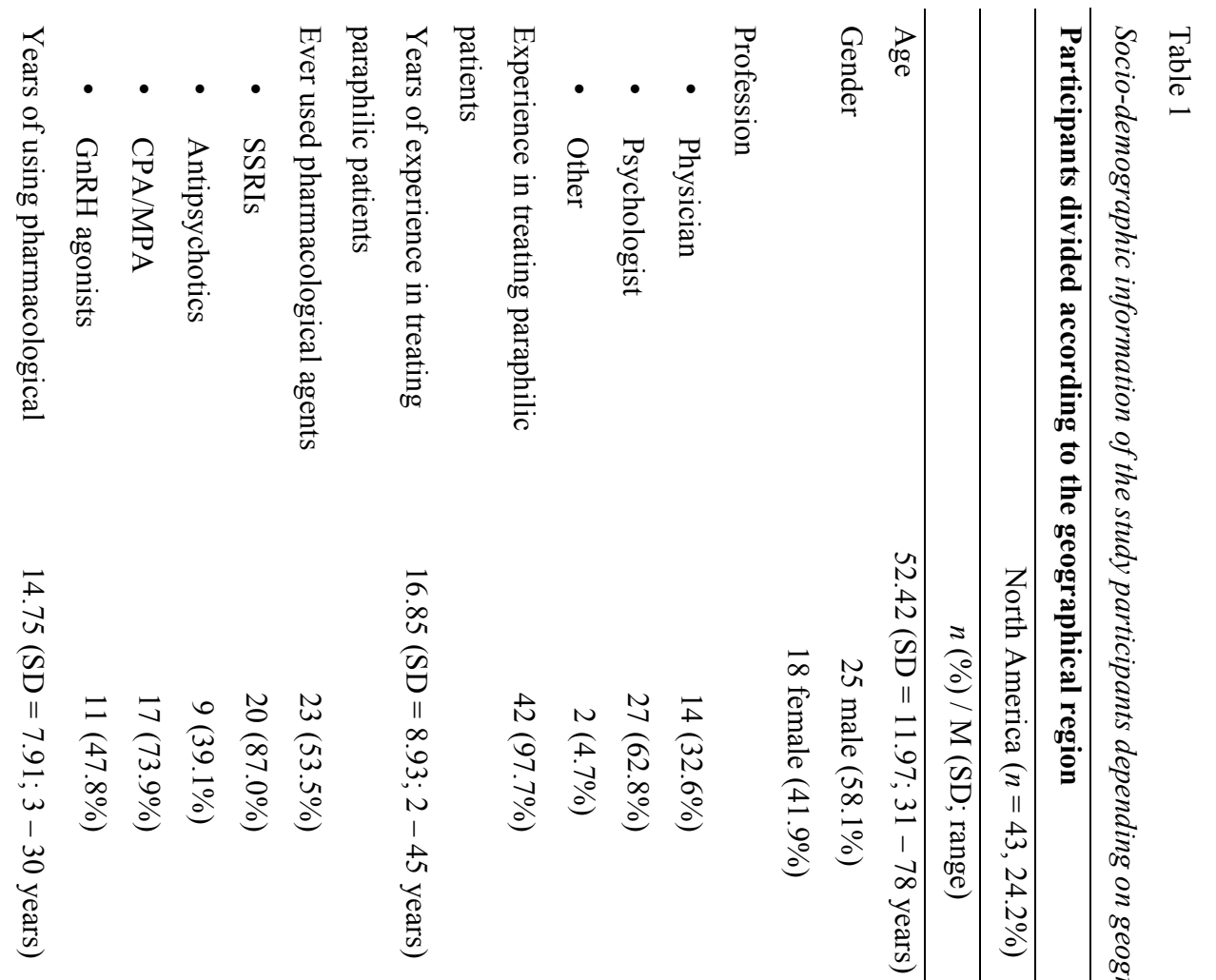

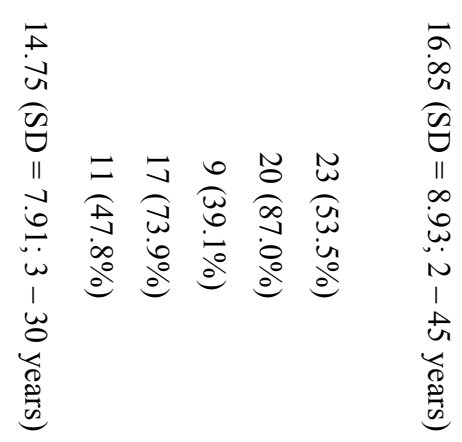

î.

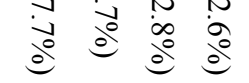

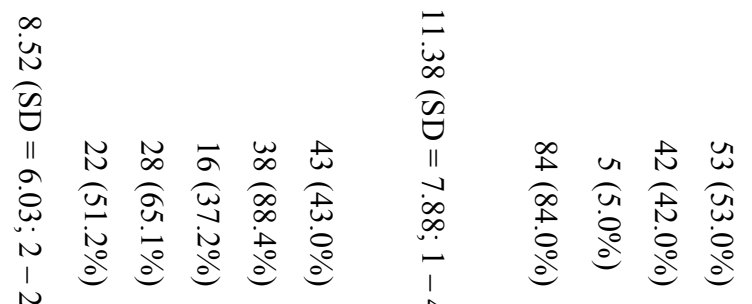
N

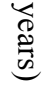

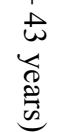

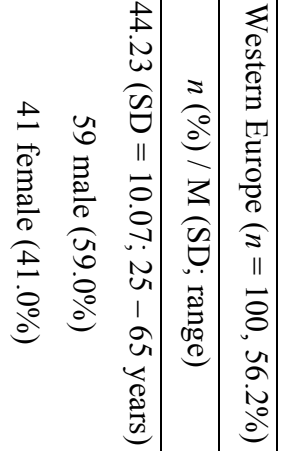

(1)

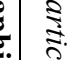

$\begin{array}{ll}\vec{\omega} & \vec{\omega} \\ \dot{\sigma} & \vec{\Delta} \\ \hat{\sigma} & \vec{\sigma}\end{array}$

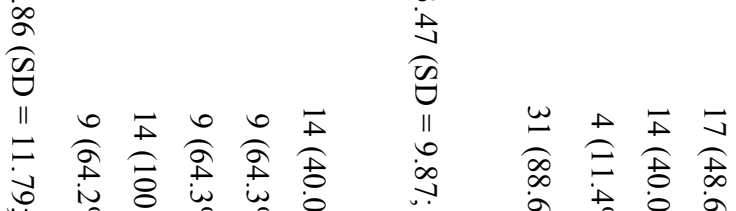

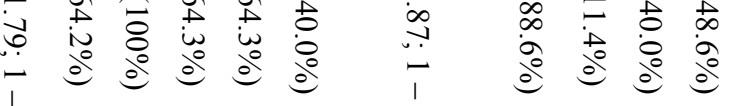

w

死

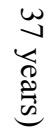

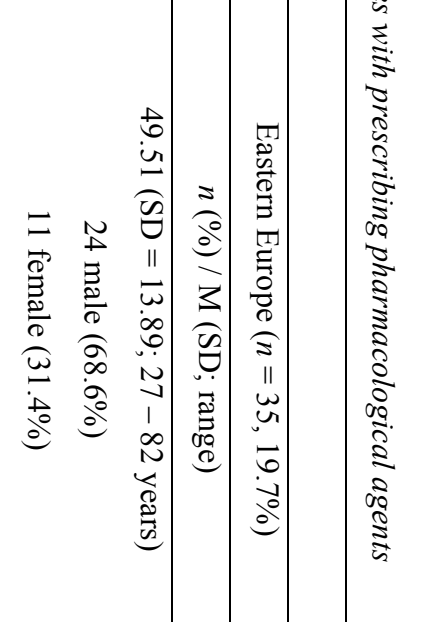




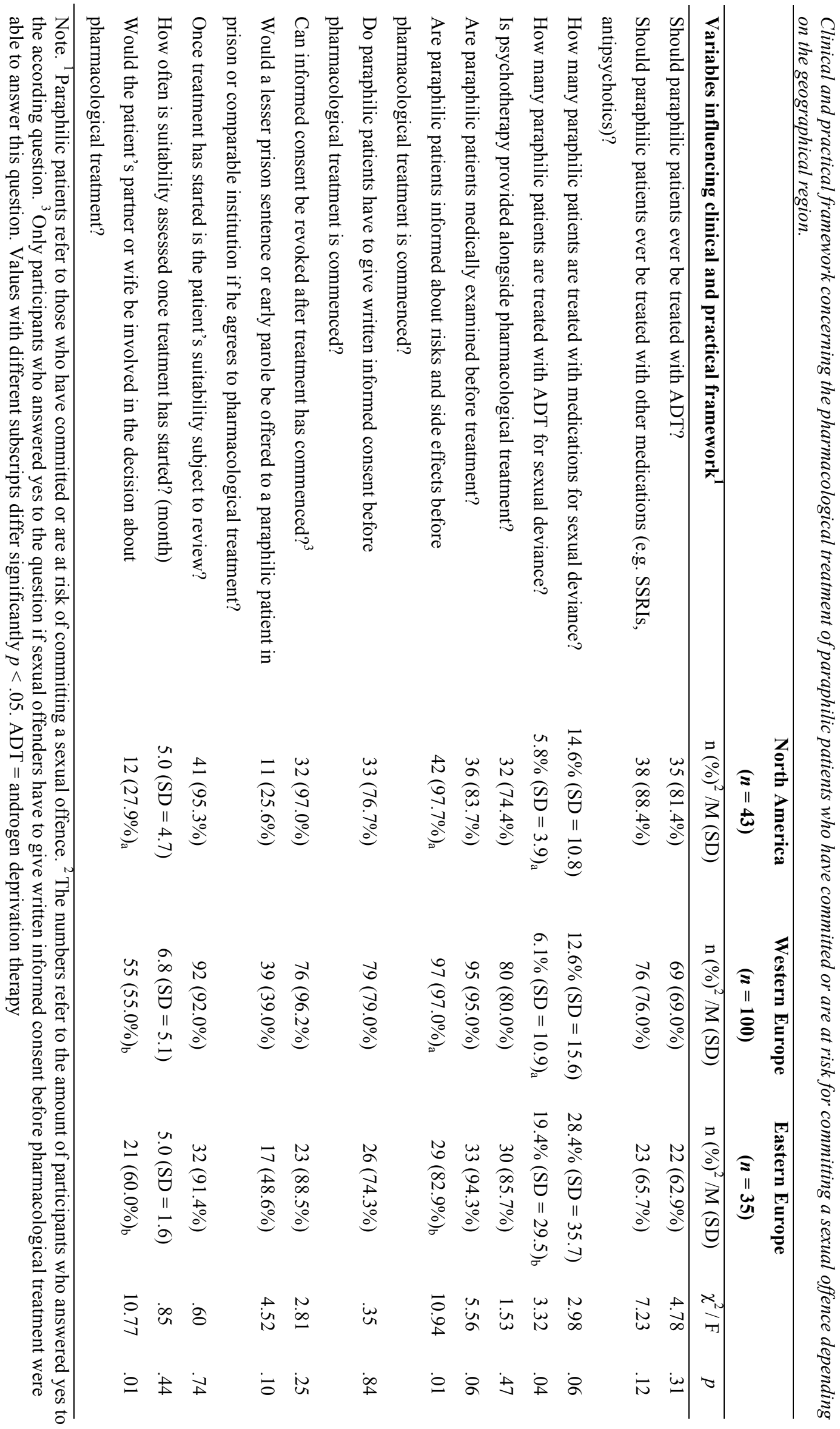


Table 3

Most appropriate treatment option depending on the paraphilic patient's risk for future sexually violent behaviours.

\begin{tabular}{|c|c|c|c|}
\hline & \multicolumn{3}{|c|}{ Risk category } \\
\hline & low & medium & high \\
\hline Treatment option & $n(\%)$ & $n(\%)$ & $n(\%)$ \\
\hline \multicolumn{4}{|c|}{ Whole sample $(n=178)$} \\
\hline Psychotherapy & $155(87.1 \%)$ & $139(78.1 \%)$ & $121(68.0 \%)$ \\
\hline SSRIs & $69(38.8 \%)$ & $83(46.6 \%)$ & $69(38.8 \%)$ \\
\hline MPA/CPA & $26(14.6 \%)$ & $87(48.9 \%)$ & $119(66.9 \%)$ \\
\hline GnRH - agonists & $14(7.9 \%)$ & $45(25.3 \%)$ & $104(58.4 \%)$ \\
\hline Surgical castration & $5(2.8 \%)$ & $10(5.6 \%)$ & $38(21.3 \%)$ \\
\hline \multicolumn{4}{|c|}{ North America $(n=43)$} \\
\hline Psychotherapy & $41(95.3 \%)$ & $40(93.0 \%)$ & $37(86.0 \%)$ \\
\hline SSRIs & $13(30.2 \%)$ & $25(58.1 \%)$ & $23(53.5 \%)$ \\
\hline MPA/CPA & $5(11.6 \%)$ & $19(44.2 \%)$ & $40(93.0 \%)$ \\
\hline GnRH - agonists & $3(7.0 \%)$ & $8(18.6 \%)$ & $26(60.5 \%)$ \\
\hline Surgical castration & 0 & 0 & $7(16.3 \%)$ \\
\hline \multicolumn{4}{|c|}{ Western Europe $(n=100)$} \\
\hline Psychotherapy & $87(87.0 \%)$ & $71(71.0 \%)$ & $59(59.0 \%)$ \\
\hline SSRIs & $44(44.0 \%)$ & $55(55.0 \%)$ & $35(35.0 \%)$ \\
\hline MPA/CPA & $9(9.0 \%)$ & $48(48.0 \%)$ & $62(62.0 \%)$ \\
\hline GnRH - agonists & $5(5.0 \%)$ & $28(28.0 \%)$ & $64(64.0 \%)$ \\
\hline Surgical castration & $2(2.0 \%)$ & $6(6.0 \%)$ & $17(17.0 \%)$ \\
\hline \multicolumn{4}{|c|}{ Eastern Europe $(n=35)$} \\
\hline Psychotherapy & $27(77.1 \%)$ & $28(80.0 \%)$ & $25(71.4 \%)$ \\
\hline SSRIs & $12(34.3 \%)$ & $3(8.6 \%)$ & $11(31.4 \%)$ \\
\hline $\mathrm{MPA} / \mathrm{CPA}$ & $12(34.3 \%)$ & $20(57.1 \%)$ & $17(48.6 \%)$ \\
\hline GnRH - agonists & $6(17.1 \%)$ & $9(25.7 \%)$ & $14(40.0 \%)$ \\
\hline Surgical castration & $3(8.6 \%)$ & $4(11.4 \%)$ & $14(40.0 \%)$ \\
\hline
\end{tabular}




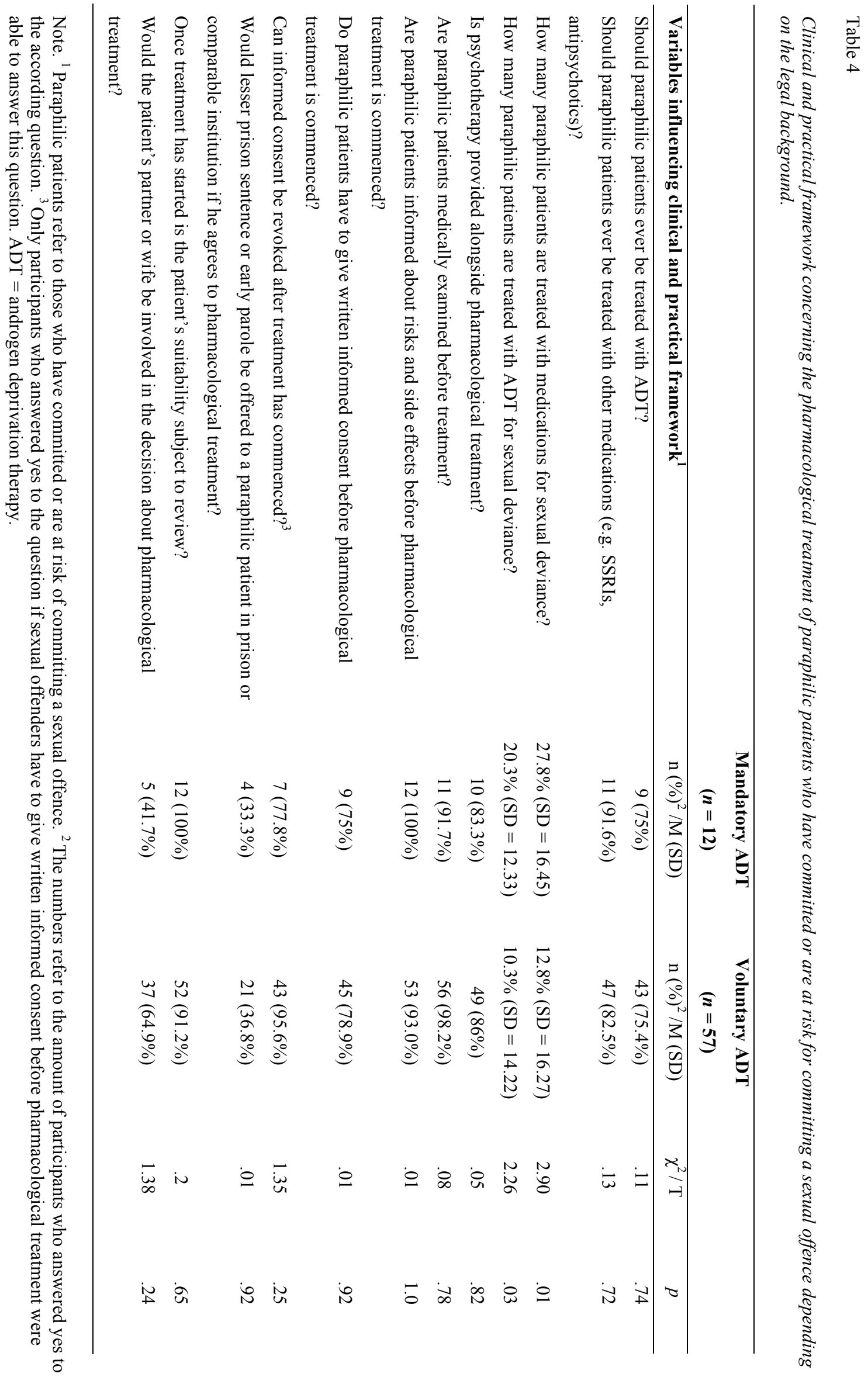

